\title{
Gestión integral del ciclo de vida del expediente y documento electrónico para cumplir con las leyes 39 y 40/2015
}

\section{José Ángel Fernández Carrasco}

GuADAlTEl S. A.

\section{Resumen}

La entrada en vigor de las Leyes 39 y 40 de 2015, que regulan respectivamente el procedimiento administrativo común y el régimen jurídico del sector público, establecen un nuevo marco jurídico para las administraciones públicas y entidades del sector público que se encuentren dentro de su ámbito subjetivo, a la hora de prestar sus servicios de forma electrónica. En el contexto de este nuevo marco normativo cobra mayor relevancia el desarrollo de soluciones tecnológicas como G-EDE, creada por Guadaltel S. A., con el objetivo de realizar la gestión integral del documento electrónico a lo largo de su ciclo de vida.

Palabras clave: Administración electrónica; Ley 39/2015; Ley 40/2015; Tecnología; Archivo electrónico único; Gestión documental

Cita recomendada: Fernández Carrasco, J. A. (2018). Gestión integral del ciclo de vida del expediente y documento electrónico para cumplir con las leyes 39 y 40/2015. En El archivo electrónico en la administración digital: 23 Jornadas de Archivos Universitarios, 21-23 de junio de 2017, A Coruña (pp. 83-91).

DOI capítulo: https://doi.org/10.17979/spudc.9788497496803.083

DOI libro: https://doi.org/10.17979/spudc.9788497496803 


\section{Introducción}

Los procesos y procedimientos que se llevan a cabo en las administraciones públicas se soportan principalmente en documentos. Estos recogen las actuaciones, decisiones y resoluciones administrativas, que evidencian el cumplimiento de los distintos pasos de la tramitación.

Las acciones normativas que han ido paulatinamente sentando las bases de la administración electrónica tienen relación directa o indirecta con la documentación administrativa (registro telemático, firma electrónica, etc.). Sin embargo, no es hasta la publicación de la Ley 11/2007 cuando se ponen de relevancia los conceptos de documento electrónico y archivo electrónico. Posteriormente, esta situación se reafirma con la entrada en vigor de la Ley 39/2015, de 1 de octubre, del Procedimiento Administrativo Común de las Administraciones Públicas y la Ley 40/2015, de 1 de octubre, de Régimen Jurídico del Sector Público.

Son necesarias herramientas tecnológicas para el tratamiento archivístico integral de los documentos de una organización, contemplando la gestión informatizada de todo tipo de documentos y expedientes, sean estos electrónicos y/o físicos, y cubriendo todas las fases de su ciclo vital: desde el archivo de oficina hasta el archivo histórico, permitiendo la comunicación electrónica y el traspaso de la información entre ellos.

De acuerdo con lo anterior, el sistema G-EDE de Guadaltel S. A. extiende el modelo de gestión documental tradicional a los documentos electrónicos, tanto los generados durante la tramitación de los diferentes procedimientos administrativos que se producen en cualquiera de los sistemas de información, como los derivados de 
expedientes que se convierten en electrónicos mediante un proceso de digitalización certificada.

El sistema contempla la gestión de un archivo mixto, al asumir tanto la convivencia de documentos electrónicos y de documentos físicos, como las tareas de digitalización de documentos y de trasformación de formatos electrónicos.

\section{Normativa y estándares}

El sistema G-EDE da respuesta a los requisitos normativos, procedimentales y de estándares de aplicación en el campo de la gestión documental electrónica y el archivo (Figura 1).

\section{ib:ede}

¿Por qué G-EDE?

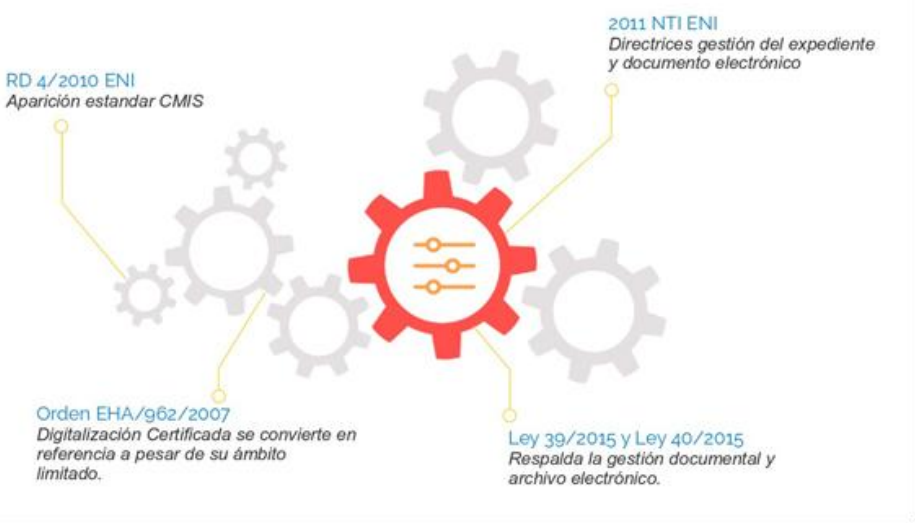

Figura 1. Evolución normativa y nacimiento de G-EDE 
En cuanto a la regulación normativa, se pueden señalar las siguientes referencias a las que el sistema da respuesta:

- Ley 39/2015, de 1 de octubre, del Procedimiento Administrativo Común de las Administraciones Públicas.

- Ley 40/2015, de 1 de octubre, de Régimen Jurídico del Sector Público.

- Real Decreto 4/2010, de 8 de enero, por el que se regula el Esquema Nacional de Interoperabilidad en el ámbito de la Administración Electrónica.

- Real Decreto 3/2010, de 8 de enero, por el que se regula el Esquema Nacional de Seguridad en el ámbito de la Administración Electrónica.

- Ley Orgánica 15/1999, de 13 de diciembre, de Protección de Datos de Carácter Personal.

- Real Decreto 1720/2007, de 21 de diciembre, por el que se aprueba el Reglamento de desarrollo de la Ley Orgánica 15/1999, de 13 de diciembre, de protección de datos de carácter personal.

- Ley 37/2007, de 16 de noviembre, sobre reutilización de la información del sector público.

- Resolución de 19 de febrero de 2013, de la Secretaría de Estado de Administraciones Públicas, por la que se aprueba la Norma Técnica de Interoperabilidad de Reutilización de recursos de la información. 
Durante el desarrollo de la solución se han tenido en cuenta múltiples normas técnicas y estándares de referencia:

- MoReq2 y MoReq2010 (Modelo de requisitos para los sistemas de gestión de documentos electrónicos de archivo): captura de información, sistema de clasificación, valoración para transferencias, gestión de calendario de conservación, medidas de auditoría, trazabilidad y seguridad, búsquedas y recuperación de la información, etc.

- Norma ISO 15489 - Gestión de documentos: referida a los sistemas de gestión documental desde la oficina.

- Norma ISO 14721 - Sistemas de transferencia de datos e información espaciales. Sistema abierto de información de archivo (OAIS).

- Norma ISO 19005 - Gestión de documentos. Formato de fichero de documento electrónico para la conservación a largo plazo (PDF/A).

- Normas internacionales y nacionales para la descripción archivística: ISAD (G), ISAAR CPF, CNEDA, Norma ISO 16175-2:2012, etc.

\section{Tecnología al servicio de la gestión documental y el archivo.}

G-EDE tiene un carácter transversal, puesto que afecta a toda la organización y está involucrada en todos los procesos. Por ello, Guadaltel S. A. orienta su desarrollo hacia su integración con el resto de sistemas de gestión a partir de una capa de interoperabilidad, pero teniendo como premisa que el impacto de dicha integración debe ser el menor posible, con acoplamiento suave. 


\section{e. G:ede}

\section{Valor diferencial de G-EDE}

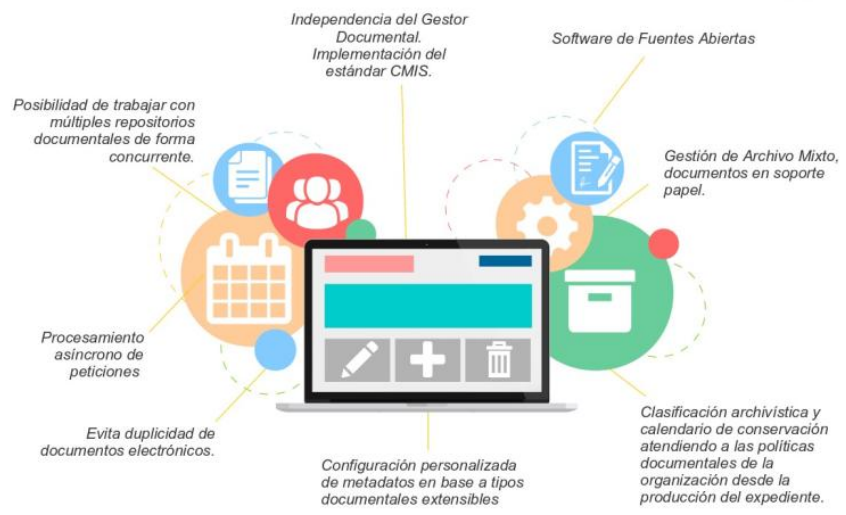

Figura 2. Valor diferencial de G-EDE

Se trata, pues, de una gestión documental integral de y para toda la organización, y que no interfiera en los sistemas de gestión de la organización (Figura 2). No obstante, el sistema permite la evolución en la gestión documental sin afectar a los sistemas de información.

Cuando se quiere conectar una aplicación de negocio con un gestor documental, las organizaciones se ven obligadas a realizar modificaciones tanto en el gestor como en las aplicaciones, de modo que se preparen ambos extremos del canal para poder comunicarse. Por ello, se ha puesto el foco en dotar de independencia al gestor documental gracias a la implementación del estándar Content Management Interoperability Services (CMIS), por ejemplo: Alfresco, Nuxeo, Documentum, etc. De esta manera, se ahorra tiempo y dinero, y se elimina el problema del versionado de los sistemas. 
Al implementar la capa de interoperabilidad con el estándar CMIS se soluciona una parte del problema, la del extremo del gestor. G-EDE se integra con el gestor documental (cualquiera que implemente CMIS), de manera que no haya que realizar modificaciones en él para prepararlo para la comunicación con las aplicaciones.

Además, ofrece todas las funcionalidades sobre expedientes $\mathrm{y}$ documentos electrónicos: foliado del expediente, generación de índices, digitalización de documentos, informes y diligencias de firma, etc. Igualmente posibilita el acceso completo e inmediato a los documentos a través de los metadatos de consulta en línea, lo que permite la visualización de los documentos con todos los detalles de su contenido, la copia o descarga en línea de formatos originales y la impresión de los documentos que sean necesarios. Se aplican en todo momento las medidas de seguridad que garantizan la integridad, autenticidad, confidencialidad, calidad, protección y conservación de los documentos almacenados.

De cara a los expedientes electrónicos, G-EDE permite la creación de índices que actúan como elementos integradores del expediente. Este índice es generado por la propia herramienta, tanto desde las interfaces web como desde el catálogo de servicios; y está compuesto por todos los metadatos del expediente, junto con los documentos que lo componen (metadatos, binario y firmas). Además, el índice se encuentra firmado electrónicamente, lo que permite garantizar la integridad del expediente a lo largo del tiempo. 
Por último, y no menos importante, se han adoptado medidas tendentes a:

- asegurar la conservación de los documentos electrónicos a lo largo de su ciclo de vida, garantizando su recuperación durante el plazo mínimo de conservación establecido en las normas administrativas. El almacenamiento es seguro (archivo securizado). En particular, se aseguran la identificación y el control de accesos de los usuarios, así como cualquier operación que se realice en el sistema, garantizando la trazabilidad de los documentos y expedientes; $\mathrm{y}$

- asegurar el valor probatorio y fiabilidad; evidencia electrónica de las actividades y procedimientos; así como la transparencia, la memoria y la identificación de los órganos de las administraciones públicas y de las entidades de derecho público vinculadas o dependientes de aquellas, que ejerzan las competencias sobre el documento o expediente.

\section{Conclusiones}

Se resumen a continuación los aspectos fundamentales de la aplicación:

- Independencia del gestor documental con el uso del estándar CMIS, con lo que G- EDE puede funcionar con la mayoría de gestores documentales actuales directa y fácilmente.

- Está basado en software de fuentes abiertas, con lo que se minimiza el número de licencias de terceros.

- Posibilidad de gestionar archivos mixtos: de documentación en papel y de la electrónica del archivo de oficina. 
- Clasificación archivística y calendario de conservación, atendiendo a las políticas documentales de la organización, desde la producción del expediente en terceras aplicaciones integradas con G-EDE.

- Configuración personalizada de tantos tipos documentales y metadatos como se necesiten, no limitándose a los descritos en el Esquema Nacional de Interoperabilidad (ENI).

- Análisis de cada fichero que se incorpora, así como su contenido, evitando la duplicidad de ficheros iguales y ahorrando espacio en el gestor documental al permitir que un mismo fichero binario pueda pertenecer a diferentes documentos electrónicos con diferentes metadatos.

- El procesamiento de los expedientes, documentos, operaciones de transferencia, etc. se realiza con tareas asíncronas y programables, que pueden tener lugar en momentos de baja carga del sistema, mejorando los tiempos de respuesta.

- Posibilidad de trabajar con múltiples repositorios documentales, lo que permite reservar ciertos gestores documentales para consulta, sin incorporar nueva información, en el caso de que carezcan de espacio o por un cambio de versión, sin la necesidad de migraciones de datos. 